\title{
EDUCAÇÃO E DESENVOLVIMENTO SUSTENTÁVEL NA AGENDA INTERNACIONAL: DE JOMTIEN (1990) A INCHEON (2015)
}

\section{EDUCATION AND SUSTAINABLE DEVELOPMENT IN THE INTERNATIONAL AGENDA: FROM JOMTIEN (1990) TO INCHEON (2015)}

\author{
ZOTTI, Solange Aparecida \\ solange.zotti@ifc-concordia.edu.br \\ IFC - Instituto Federal Catarinense - Campus Concórdia, SC \\ VIZZOTTO, Liane \\ liane.vizzotto@ifc-concordia.edu.br \\ IFC - Instituto Federal Catarinense - Campus Concórdia \\ CORSETTI, Berenice \\ bcorsetti@unisinos.br \\ UNISINOS - Universidade do Vale do Rio dos Sinos
}

\begin{abstract}
RESUMO Nas últimas décadas a educação passa a ser chamada para tomar sua responsabilidade na concretização de um planeta sustentável. Nesse sentido, o objetivo dessa reflexão é discutir a concepção de educação para o desenvolvimento sustentável em documentos oficiais transnacionais dos quais o Brasil é signatário. A pesquisa caracteriza-se como documental, sendo analisados os documentos: Década das Nações Unidas da Educação para o Desenvolvimento Sustentável (2005-2014) e as produções das Conferências de Jomtien (1990), Dakar (2000) e Incheon (2015). As análises evidenciam a relação educação e desenvolvimento sustentável, como um elemento importante do conjunto das orientações dos organismos multilaterais, mas revelam um discurso reformista, cuja superação de modelos externos e voltados ao capital está longe de se efetivar.
\end{abstract}

Palavras-chave: Conferências de Educação. Desenvolvimento Sustentável. Educação. Organismos Multilaterais.

\begin{abstract}
In the last decades education is being called to take its responsibility in the embodiment of a sustainable planet. In this sense, the goal of this reflection is to discuss the concept of education for the sustainable development in official transnational documents in which Brazil is the signatory. The research features itself as documentary research, being the following documents analysed: The United Nations Decade for Sustainable Development (2004-2014) and the productions of the Jomtien (1990), Dakar (2000) and Incheon (2015) conferences. The analysis evidence the education and sustainable development relationship, as an important element of the multilateral organisms guidelines, although revealing a reformist discourse, whose overcoming of external and capital-oriented models is far from becoming effective.
\end{abstract}

Keywords: Education Conferences. Sustainable development. Education. Multilateral Organisms. 


\section{INTRODUÇÃO}

Nas últimas décadas tem sido recorrente o discurso da sustentabilidade. $\mathrm{O}$ desenvolvimento sustentável marca atualmente uma ideologia que deve promover ações nos âmbitos econômicos e sociais. De empresas às escolas, o desenvolvimento sustentável torna-se para além da retórica, uma ação.

Mas, o que se entende por desenvolvimento sustentável e que relação guarda com a educação?

A necessidade de conservar o ambiente por meio de práticas com menor impacto ambiental foi pauta de Conferências organizadas pela Organização das Nações Unidas (ONU), ainda nos anos de 1970. Já, o conceito de sustentabilidade surge na década de 1980 decorrente da necessidade de equilibrar $\theta$ progresso econômico e social. Em 1987, a Comissão Mundial sobre Meio Ambiente e Desenvolvimento das Nações Unidas, por meio do relatório Brundtland ${ }^{1}$, intitulado "Nosso Futuro Comum", tornou mais conhecida a expressão "desenvolvimento sustentável", que prima pelo desenvolvimento atual sem comprometer a capacidade das gerações futuras no atendimento de suas próprias necessidades (UNESCO, 2005). Essa preocupação se transforma em pauta de Conferências quando impactos ambientais começam a ser vistos no mundo, de modo a se admitir que o planeta não suportaria a permanência do modelo de desenvolvimento adotado até o momento, caracterizado pela produção e consumo exacerbado e, por outro lado, gritantes diferenças econômicas ao redor do mundo.

Esse debate se situa na lógica de um novo pensamento ecológico que se opõe ao discurso do ambientalismo, ou seja, não é mais suficiente a discussão da proteção do meio ambiente. A visão se coloca na escolha precisa de que tipo de desenvolvimento se deseja implementar uma vez que desenvolvimento e meio ambiente deixaram de ser considerados realidades antagônicas, mas complementares. Portanto, a escolha situa-se entre que estilo de desenvolvimento se deseja, visto que o modelo convencional adotado pelo ocidente não conseguiu resolver os problemas econômicos no Terceiro Mundo, ao mesmo tempo em que os

\footnotetext{
${ }^{1}$ Em 1983, a médica Gro Harlem Brundtland, mestre em saúde pública e ex-Primeira Ministra da Noruega, foi convidada pela ONU para estabelecer e presidir a Comissão Mundial sobre o Meio Ambiente e Desenvolvimento, por este motivo a comissão e o relatório ficaram conhecidos pelo seu nome (ONUBR, 2016).
} 
graves problemas ambientais também revelaram a necessidade de alterar o modelo (LAYRARGUES, 1997).

A educação também passa a ser chamada para tomar sua responsabilidade na concretização de um planeta sustentável. A educação para o desenvolvimento sustentável tornou-se premissa do trabalho escolar, sendo as Conferências de Educação e os Organismos Multilaterais os principais propositores e difusores transnacionais dessa temática.

Nesse sentido, o objetivo dessa reflexão é discutir a concepção de educação para o desenvolvimento sustentável em documentos oficiais transnacionais dos quais o Brasil é signatário, percebendo como vai evoluindo a partir das conexões com outros discursos.

Para tanto, tomamos em particular os documentos do âmbito educacional que expressam não apenas a educação para o desenvolvimento sustentável, mas aqueles que incorporaram o discurso numa linguagem clara do papel da educação frente às questões da sustentabilidade.

Tomaremos para análise o documento "Década das Nações Unidas da Educação para o Desenvolvimento Sustentável (2005-2014)" que, especificamente, aponta as diretrizes orientadoras que devem ser observadas na implementação das políticas educacionais dos países signatários. Também, faremos uma incursão nos documentos produzidos em Jomtien, na Tailândia (1990) e na Conferência de Dakar (2000), visto a importância de ambos na concepção da educação nos diversos países. Por fim, a Conferência de Incheon (2015) passa atualmente a ser aquela que revigora o debate educacional.

Em que pese os documentos serem objetos de inúmeras publicações no campo da educação, a relação educação e desenvolvimento sustentável não é comum em trabalhos. Os apontamentos que seguem neste artigo contribuem para evidenciar mais elementos da educação contidos nas sistematizações dos diversos órgãos que compõem o conjunto dos organismos multilaterais. Ressaltamos que a análise dos documentos se desenvolve em sua relação com o contexto no qual foram produzidos.

Na primeira seção apresentamos o conceito de desenvolvimento sustentável e sua trajetória histórica no contexto educacional. Quando e como o conceito bateu na porta da educação se manifesta como marcos temporal e conceitual necessário à reflexão. Em um segundo momento, procuramos mostrar o entendimento do papel da 
educação para o desenvolvimento sustentável nos documentos transnacionais supracitados. A contextualização das concepções acerca do tema se faz necessária. Por isso, dispensamos em uma breve seção, uma reflexão sobre educação para o desenvolvimento sustentável e alívio da pobreza, pois ambos os discursos aparecem nos documentos e se relacionam.

Salientamos que ao olhar o tema nos documentos proclamados por agências internacionais, tomamos como pressuposto teórico o materialismo histórico dialético. A contribuição dessa concepção marxiana nos permite refletir, por meio da totalidade dos elementos, que a priori se apresentam como prontos e acabados, as relações e os interesses econômicos em períodos particulares do desenvolvimento do modo de produção capitalista.

\section{O DESENVOLVIMENTO SUSTENTÁVEL NA EDUCAÇÃO - TRAJETÓRIA E CONCEITO}

O debate em torno do desenvolvimento sustentável ultrapassou as fronteiras territoriais e aproximou-se dos diversos campos da vida social.

A emergência do discurso da sustentabilidade é decorrente da década de 1970, cujos sinais são vistos nos diversos movimentos sociais em defesa da ecologia que se manifestaram ao redor do mundo. Além desses, as Conferências internacionais promovidas pela ONU com o fim de debater temas do meio ambiente $\mathrm{e}$ desenvolvimento também compuseram o cenário de preocupação com as questões ambientais. Outras manifestações, como o Relatório do Clube de Roma (1972), intitulado "Os Limites do Crescimento" e trabalhos de pioneiros de diversos campos convergiam para as mesmas preocupações (LIMA, 2003).

A necessidade de estabelecer formas que equilibrassem a vida dos seres humanos com questões ambientais exigiu da educação uma participação efetiva, especialmente após a proclamação da "Década das Nações Unidas da Educação para o Desenvolvimento Sustentável" (2005-2014), sistematizada pela UNESCO, órgão designado pela ONU para esse fim. O documento se caracteriza como um plano internacional e "descreve o tipo de educação que, coletivamente, os parceiros consideram essencial para facilitar o desenvolvimento sustentável" (UNESCO, 2005, p. 24). Os trabalhos se iniciaram em 2002 e são resultados de consultas a agências 
das Nações Unidas, governos nacionais, organizações da sociedade civil e especialistas.

A Década da Educação utiliza o conceito da Comissão Brundtland, a qual define que "desenvolvimento sustentável é o desenvolvimento que resolve as necessidades atuais sem comprometer a capacidade das gerações futuras de também satisfazerem suas próprias necessidades" (UNESCO, 2005, p. 29). Esse entendimento, segundo Guerra et al (2016, p. 71), "[,,,] é anteriormente discutido por Sachs (1986) quando enunciou as dimensões da sustentabilidade necessária ao planejamento do desenvolvimento".

As referências mais explícitas sobre o entendimento de desenvolvimento sustentável são sistematizações dos trabalhos de Ignacy Sachs (1986), cuja formulação resultou na noção de Ecodesenvolvimento que procurava articular a promoção econômica, preservação ambiental e participação social. "Perseguia, com especial atenção, meios de superar a marginalização [...], portanto, marcante em seus trabalhos o compromisso com os direitos e desigualdades sociais" (LIMA, 2003, p. 102). Além disso, nessa visão o desenvolvimento deve ser pensado em cada ecorregião, com soluções específicas de seus problemas particulares, levando em conta as questões ecológicas e as culturais, as necessidades imediatas e as a longo prazo. Não nega a importância dos intercâmbios, mas contesta a visão predominante das soluções universalistas e generalizadas. Não descarta, mas não atribui importância excessiva à ajuda externa, apostando na capacidade das sociedades humanas de identificar os seus problemas e buscar soluções, ainda que inspiradas em experiências alheias (SANCHS, 1986 apud LAYRARGUES, 1997, p. 03).

No entanto, a Comissão Brundtland mesmo apoiada em muitas das ideias apontadas por Sachs, chegou a um entendimento diferente, especialmente naquilo que seria inovador - o conteúdo emancipador do Ecodesenvolvimento. O conceito adotado pela ONU preservou a articulação de crescimento econômico, preservação ambiental e equidade social, cuja combinação despolitizou a proposta de Sachs e o discurso da sustentabilidade surgiu como substituto da retórica do desenvolvimento econômico ${ }^{2}$, que foi produzido e difundido pelos países centrais do capitalismo, especialmente os Estados Unidos. Desse modo, o foco da discussão dos problemas

\footnotetext{
${ }^{2}$ Mais adiante retomaremos esse debate, pois sua relação com os objetivos para alívio da pobreza são
} fundantes nas reformas. 
ambientais se volta para o entendimento de que eles eram resultantes do modelo de produção posto em prática. Lima (2003) ressalta que toda essa orientação da ideia de desenvolvimento se deu no contexto de crise do próprio capitalismo e da hegemonia do pensamento neoliberal nos anos de 1980 .

As bases conceituais oficializadas pelos organismos internacionais são apenas uma das matrizes interpretativas do desenvolvimento sustentável, considerada como discurso oficial. Elas têm como fundamento a possibilidade de conciliação entre economia e ecologia, como também o entendimento de que é possível elevar a produção com introdução de tecnologias limpas. Por outro lado, há outra matriz que se opõe à visão oficial, a qual prioriza o preceito de equidade social e desconfia da capacidade do mercado como alocador de recursos (LIMA, 2003). Desse modo, os defensores dessa segunda matriz, entendem que "não há sustentabilidade possível sem a incorporação das desigualdades sociais e políticas [...]" (LIMA, 2003, p. 109).

Com base na consolidada constatação de que o planeta é um só e é finito, na visão da ONU, conforme a Comissão Brundtland, se os problemas são comuns, a resolução dos problemas demandariam esforços também comuns a todos. Essa concepção tira de cena um dos principais aspectos proposto por Sachs, ou seja,

[..] independente da existência de atores sociais implicados na responsabilidade da degradação ambiental, a busca de soluções seria uma tarefa comum à toda humanidade. Na tentativa de generalizar os fatos, omite um contexto histórico, e cria o "homem abstrato", cuja consequência significa a retirada do componente ideológico da questão ambiental, que passa a ser considerada com uma certa dose de ingenuidade e descompromisso, frente à falta de visibilidade do procedimento histórico que gerou a crise ambiental (LAYRARGUES, 1997, p. 04).

O Relatório da Comissão Mundial sobre Meio Ambiente e Desenvolvimento (CMMAD) - Comissão Brundtland - elabora um novo conceito de desenvolvimento sustentável, mas afirmando que o mesmo tem limites, não absolutos, mas impostos pelo estágio atual da tecnologia, da organização social e em relação às questões ambientais a capacidade da biosfera de absorver os efeitos da atividade humana. Entretanto, entende que é possível gerir e aprimorar a tecnologia e a organização social para uma nova era de crescimento econômico (LAYRARGUES, 1997).

Outro aspecto central do Relatório é a relação desenvolvimento sustentável e combate à pobreza: 
[...] para haver um desenvolvimento sustentável é preciso atender às necessidades básicas de todos e dar a todos a oportunidade de realizar suas aspirações de uma vida melhor. Um mundo onde a pobreza é endêmica estará sempre sujeito a catástrofes, ecológicas ou de outra natureza (CMMAD, 1988 apud LAYRARGUES, 1997, p. 04).

A pobreza é considerada uma das principais causas e um dos principais efeitos dos problemas ambientais no mundo. Por isso, não é possível tentar a resolução desses problemas, sem que englobe os fatores subjacentes à pobreza mundial e à desigualdade internacional. Nesse sentido, os documentos abordam claramente o papel da educação no combate à pobreza e na promoção do desenvolvimento. Conforme Layrargues (1997), tal ideia do combate à pobreza tem o propósito de justificar a necessidade da continuidade do crescimento econômico, bem como omitir o peso da responsabilidade ambiental do consumo excessivo do Norte, a poluição da riqueza.

A Educação para o desenvolvimento sustentável é reforçada na Agenda 21, capítulo 36, da Conferência das Nações Unidas sobre o Meio Ambiente e desenvolvimento - Rio de Janeiro, 1992. Nesse capítulo são endossadas as recomendações da Conferência Mundial de Educação para Todos, ou seja, a satisfação das necessidades de aprendizagens, definidas pela Conferência de Jomtien, em 1990.

Tomando como base o conceito oficial de desenvolvimento sustentável, as conferências educacionais transnacionais têm tratado da sustentabilidade como um fator fundante para a solução das questões ambientais desde Jomtien (1990) à Incheon (2015). Em cada uma delas há a reafirmação de concepções anteriores, aliando a novos discursos que passam a compor a agenda educacional. Porém, o caráter reducionista de desenvolvimento sustentável, atribuído pela pretensa concepção de mercado presente nos documentos oficiais, tem colocado as complexas articulações do conceito em um nível ilusório ou insustentável (LIMA, 2003). O apelo às questões sociais parece obscurecer as intenções reais que os documentos escondem quando colocam "a educação como fator estratégico no desenvolvimento de valores que conduzem ao desenvolvimento sustentável" (UNESCO, 2005, p. 43). É este o papel afirmado para a educação nos países não desenvolvidos, aliado ao discurso ideológico que acentua a erradicação da pobreza como fator central para o 
desenvolvimento sustentável, como se o problema fosse somente a "poluição da pobreza", sendo omitida da discussão, a questão da "poluição da riqueza".

Tendo em vista as interpretações de desenvolvimento sustentável decorrentes da vertente oficial, a materialização do discurso na educação também assume forma, como veremos em cada documento.

\section{EDUCAÇÃo E DESENVOLVIMENTO SUSTENTÁVEL: O QUE DIZEM OS DOCUMENTOS OFICIAIS TRANSNACIONAIS}

De acordo com o objetivo deste artigo, temos como ponto de partida a "Declaração Mundial sobre Educação para Todos: Plano de Ação para Satisfazer as Necessidades Básicas de Aprendizagem", aprovada pela Conferência Mundial sobre Educação para Todos, que aconteceu em Jomtien, Tailândia, de 5 a 9 de março de 1990. A Declaração de Jomtien está em consonância com as diretrizes e objetivos traçados pelos organismos internacionais como o Banco Mundial (BM), Fundo Monetário Internacional (FMI), Banco Internacional para Reconstrução e Desenvolvimento (BIRD), Organismo Multilateral de Garantia de Investimento (MIGA) e Programa das Nações Unidas para o Desenvolvimento (PNUD). Para essas organizações a educação é concebida como uma solução para o combate à pobreza e sua responsabilidade é da comunidade, da família e do Estado.

O documento inicia constatando que a Declaração Universal dos Direitos Humanos, há mais de quarenta anos, afirmou que "toda pessoa tem direito à educação". Contudo, os dados apontam que esse direito não está assegurado em muitos países do mundo, evidenciando as principais problemáticas:

- mais de 100 milhões de crianças, das quais pelo menos 60 milhões são meninas, não têm acesso ao ensino primário;

- mais de 960 milhões de adultos - dois terços dos quais mulheres são analfabetos, e o analfabetismo funcional é um problema significativo em todos os países industrializados ou em desenvolvimento;

- mais de um terço dos adultos do mundo não têm acesso ao conhecimento impresso, às novas habilidades e tecnologias, que poderiam melhorar a qualidade de vida e ajudá-los a perceber e a adaptar-se às mudanças sociais e culturais; e

- mais de 100 milhões de crianças e incontáveis adultos não conseguem concluir o ciclo básico, e outros milhões, apesar de concluí-lo, não conseguem adquirir conhecimentos e habilidades essenciais (UNESCO, 1990, p. 01). 
Além destes dados alarmantes em relação à educação, o documento destaca outros problemas a enfrentar no mundo, como o aumento da dívida de muitos países, a crise econômica e as diferenças crescentes entre as nações e nos próprios países; o rápido aumento da população; a guerra, as lutas civis, a violência; a morte de milhões de crianças e, por fim, destaca a degradação generalizada do meio ambiente. Essa realidade, conforme o documento dificulta as ações para garantir a satisfação das necessidades básicas de aprendizagem e o acesso à educação básica de significativas parcelas da população, o que impede que a sociedade busque soluções para os problemas apontados. Nesse sentido, durante a década de 1980 , foram os países menos desenvolvidos que tiveram maior dificuldade para estender a educação básica para a maioria de sua população.

Por outro lado, o avanço das informações e da comunicação, as inovações e pesquisas, as experiências que demonstram o progresso em educação de muitos países indicam, conforme o documento, que a educação básica para todos é uma meta viável, para a garantia da educação como um direito fundamental de todos. Referenda também "que a educação pode contribuir para conquistar um mundo mais seguro, mais sadio, mais próspero e ambientalmente mais puro, e que, ao mesmo tempo, favoreça o progresso social, econômico e cultural, a tolerância e a cooperação internacional' (UNESCO, 1990, p. 03, grifo nosso). Assim, mesmo não aparecendo no documento o termo "desenvolvimento sustentável", é enfatizado o papel da educação para este fim em coerência com o relatório "Nosso Futuro Comum" (1987) da Comissão Mundial sobre Meio Ambiente e Desenvolvimento (CMMAD). Este relatório define como objetivo:

Propor estratégias ambientais de longo prazo para se obter um desenvolvimento sustentável por volta do ano 2.000 e daí em diante; recomendar maneiras para que a preocupação com o meio ambiente se traduza em maior cooperação entre os países em desenvolvimento e entre países em estágios diferentes de desenvolvimento econômico e social e leve à consecução de objetivos comuns e interligados que considerem as interrelações de pessoas, recursos, meio ambiente e desenvolvimento (CMMAD, 1988 apud LAYRARGUES, 1997, p. 04, grifo nosso).

Em consonância com as políticas do Banco Mundial, a educação é tratada

[...] como uma estratégia política e uma variável econômica capaz de impulsionar o pretendido desenvolvimento e a redução da pobreza: de forma condizente, portanto, com o discurso do Milênio e, como não poderia deixar 
de ser, com as necessidades de reprodução do capital (JIMENEZ; MENDES SEGUNDO, 2007, p. 123).

Para esse fim, uma proposição central da Conferência foi deslocar o eixo do debate educacional, especialmente no chamado Terceiro Mundo, do tema da "alfabetização" para a "educação básica". A alfabetização passa a ser incluída no conceito de educação básica, bem como a proposição de ações para a universalização desta (GADOTTI, 1991). O Documento de Referência da Conferência Mundial de Jomtien "Satisfazendo as necessidades básicas de aprendizagem uma visão para os anos 90", assim definiu a educação básica:

A educação básica refere-se à educação que objetiva satisfazer as necessidades básicas de aprendizagem; inclui a instrução primária ou fundamental, em que a aprendizagem subsequente deve ser baseada; compreende a educação infantil e primária (ou elementar), bem como a alfabetização, cultura geral e habilidades essenciais na capacitação de jovens e adultos; em alguns lugares inclui também o ensino médio (apud GADOTTI, 1991, p. 02).

Para enfrentar a amplitude dos desafios, a Declaração Mundial sobre Educação para Todos foi composta de dez artigos que apresentam os principais objetivos a serem perseguidos e implantados pelos países signatários. O primeiro artigo trata de satisfazer as necessidades básicas de aprendizagem que se referem "aos conhecimentos, habilidades, atitudes e valores necessários para as pessoas sobreviverem, desenvolverem a qualidade de suas vidas e continuarem aprendendo" (apud GADOTTI, 1991, p. 02). Estes aspectos são essenciais, conforme o documento, para o desenvolvimento da sociedade. No decorrer deste objetivo encontramos menção de que a satisfação das necessidades básicas de aprendizagem permite às pessoas contribuir, dentre outros aspectos, com a causa da justiça social e de proteger o meio-ambiente.

O segundo artigo refere-se a "Expandir o enfoque" da educação básica e também aponta para a relação educação e desenvolvimento, nos seguintes termos: "a concretização do enorme potencial para o progresso humano depende do acesso das pessoas à educação e da articulação entre o crescente conjunto de conhecimentos relevantes com os novos meios de difusão desses conhecimentos" (UNESCO, 1990, p. 06, grifo nosso). Nos artigos seguintes não identificamos objetivos mais específicos e diretos da relação educação e desenvolvimento sustentável. O que 
verificamos é a reafirmação constante do objetivo fundamental e central da Declaração: satisfazer as necessidades básicas da aprendizagem de todas as crianças, jovens e adultos, considerado o meio mais eficaz de fomentar a equidade.

No documento, encontramos o Plano de Ação para Satisfazer as Necessidades Básicas de Aprendizagem, com a finalidade de atingir os objetivos estabelecidos na Declaração. O plano compreende três grandes níveis de ação conjunta: "(i) ação direta em cada país; (ii) cooperação entre grupos de países que compartilhem certas características e interesses; e (iii) cooperação multilateral e bilateral na comunidade mundial" (UNESCO, 1990, p. 14). Prevê que cada país poderá estabelecer suas próprias metas para a década de 1990, mas que estejam em consonância com as seis dimensões propostas no documento, a saber: 1. Expansão dos cuidados básicos e atividades de desenvolvimento infantil; 2. Acesso universal e conclusão da educação fundamental até o ano 2000; 3. Melhoria dos resultados de aprendizagem; 4. Redução da taxa de analfabetismo adulto à metade; 5 . Ampliação dos serviços de educação básica e capacitação em outras habilidades essenciais necessárias aos jovens e adultos; 6. Aumento da aquisição dos conhecimentos, habilidades e valores necessários a uma vida melhor e um desenvolvimento racional e constante.

Portanto, é a sexta dimensão que indica o papel da educação frente o desenvolvimento sustentável, vinculando o "aumento do conhecimento" como necessário para a melhoria da qualidade de vida e do desenvolvimento, tratado como "racional e constante", conforme o texto integral transcrito a seguir:

6. Aumento da aquisição, por parte dos indivíduos e famílias, dos conhecimentos, habilidades e valores necessários a uma vida melhor e um desenvolvimento racional e constante, por meio de todos os canais da educação - inclusive dos meios de comunicação de massa, outras formas de comunicação tradicionais e modernas, e ação social -, sendo a eficácia destas intervenções avaliadas em função das mudanças de comportamento observadas (UNESCO, 1990, p. 17).

Em suma, a educação compensatória aparece com nova roupagem, exibindo a noção de equidade, relacionada à competência e à ação do indivíduo de conquistar seu espaço e ainda contribuir para com a sociedade. À educação, a partir do princípio da equidade, cabe a tarefa de promover a cidadania e a inclusão social, a fim de ajustar os indivíduos e os países (pobres) às exigências do novo milênio (JIMENEZ; MENDES SEGUNDO, 2007). Conforme as autoras, Jomtien e outras Conferências 
posteriores reafirmam as tese da teoria do capital humano em relação ao papel da educação como:

[...] condição primordial para o enfrentamento dos problemas socioeconômicos, através do combate à pobreza, do aumento da produtividade, da melhoria das condições de vida e da proteção ao meio ambiente, levando, de quebra, a que seus "cidadãos assumam seu papel por direito na construção de sociedades democráticas e no enriquecimento de sua herança cultural" (JIMENEZ; MENDES SEGUNDO, 2007, p. 8).

A conferência de Jomtien entende que "a Educação é o cimento para a construção do desenvolvimento humano sustentável (DELORS, 1994, p. 236)". Isso porque deve primar por melhores condições de vida para todos e, para haver o acesso a todos na perspectiva de viver melhor, é necessário melhorar os conhecimentos através de uma educação permanente a ser desenvolvida, não só pelo poder público, mas também pelo setor produtivo (DELORS, 1994). O enfoque dado à educação básica inclui "um conjunto de conhecimentos e de competências indispensáveis na perspectiva do desenvolvimento humano" (DELORS, 1994, p. 80), ou melhor, do desenvolvimento humano sustentável. Grosso modo, as decisões de Jomtien em relação à educação, conduzem-na para o atendimento das necessidades básicas dos sujeitos por meio de políticas equitativas, cuja concepção versa sobre a vinculação entre conhecimento e qualidade de vida ou, como vimos, uma educação que possibilite o desenvolvimento humano sustentável.

O documento "Década das Nações Unidas da Educação para o Desenvolvimento Sustentável (2005-2014) (EDS)" (UNESCO, 2005), explicita unicamente o assunto sobre Educação para o Desenvolvimento Sustentável.

A EDS marca a preocupação da comunidade internacional com as questões relativas ao desenvolvimento sustentável, pois desde Jomtien e, em particular os Objetivos de Desenvolvimento do Milênio (Dakar), buscam alcançar impactos similares na redução da pobreza à melhoria da qualidade de vida. Mas isso perpassa pelo entendimento do papel central da educação para a melhoria da qualidade almejada e o lugar que ocupa a Década da Educação para o Desenvolvimento Sustentável nessas iniciativas. A Educação para o desenvolvimento sustentável focaliza, assim, os princípios e valores transmitidos por intermédio da educação e volta-se mais que as iniciativas anteriores para o conteúdo e o propósito da educação e, mais amplamente, para todos os tipos de ensino. 
Dessa forma, "a educação é condição sine qua non para o desenvolvimento sustentável" (UNESCO, 2005, p. 37). E por que eleger a educação para tal condição? Porque o elemento humano é fundamental para marcar as relações que são estabelecidas e o rumo que se dá ao desenvolvimento sustentável: "[...] tanto as relações sociais e econômicas entre as pessoas e instituições quanto às relações entre sociedade e recursos naturais é que facilitarão ou dificultarão o progresso em direção ao desenvolvimento sustentável" (UNESCO, 2005, p. 38).

Frente a essa concepção, a educação, para os organismos internacionais, assume um papel específico, a saber, o desenvolvimento de valores.

\begin{abstract}
As relações humanas fundamentadas no próprio interesse (ganância, inveja e ambição pelo poder, por exemplo) mantêm uma distribuição de riqueza injusta, que gera conflito e leva a menosprezar a disponibilidade futura dos recursos naturais. Ao contrário, as relações caracterizadas pela justiça, paz e negociação de interesses mútuos geram mais igualdade, respeito e compreensão. São estas qualidades que irão fundamentar 0 desenvolvimento sustentável (UNESCO, 2005, p. 43).
\end{abstract}

Embora o documento transpareça a ideia de que a educação sozinha não fará todas as mudanças necessárias rumo a uma sociedade sustentável, ela é o principal meio que "junto com motivações espirituais positivas, a educação é a nossa melhor oportunidade de promover e enraizar os valores e comportamentos que 0 desenvolvimento sustentável exige" (UNESCO, 2005, p. 43).

Segundo a EDS, as características da educação devem estar em consonância com os objetivos da Educação para Todos (especialmente o item 6), uma vez que visa oferecer para todos uma educação de qualidade que leve a resultados de aprendizagem de excelência e mensuráveis. A Educação para o desenvolvimento sustentável deve abranger a todas as disciplinas, não podendo ser entendida estritamente como educação ambiental. Por isso ela deve ser holística e interdisciplinar, possuir valores direcionados, os quais devem servir de base para o desenvolvimento sustentável. Deve ainda favorecer o pensamento crítico e as soluções de problemas, passar de um ensino que valorize mais que a simples transmissão do conhecimento, os alunos devem participar do processo de tomada de decisão, ser aplicável, ou seja, a Educação para o Desenvolvimento Sustentável compreende que as experiências de aprendizagem oferecidas estão integradas no 
cotidiano tanto pessoal quanto profissional e, por fim, ser localmente aplicada (UNESCO, 2005).

Do ponto de vista do desenvolvimento sustentável, a redução da pobreza tornase o ponto central do elemento econômico, mas deve ser entendida em relação aos outros três elementos: o social, o ambiental e o cultural. Em outras palavras, considerações econômicas, ainda que fundamentais para o desenvolvimento sustentável, são fatores de contribuição, ao invés de objetivo primordial (UNESCO, 2005).

Nesse documento, em que pese o discurso suave da relação entre educação e alívio da pobreza, a educação para o desenvolvimento sustentável é vista como aliada à redução da pobreza, mas esse mesmo monólogo esconde o papel exercido pelo capital e suas formas na constituição das camadas pobres da população mundial, bem como na deterioração do meio ambiente devido ao consumo exacerbado, mas essencial na visão de desenvolvimento defendida pelo mercado.

De modo geral, a EDS prima por uma educação sustentável de forma direta em relação aos demais documentos. Reafirma as teses indicadas na Conferência de Jomtien acerca do papel da educação e também prima para que ao aluno lhe seja dada autonomia na resolução dos problemas.

A Conferência de Dakar, que ocorreu de 26 a 28 de abril de 2000, em Dakar Senegal reassume os compromissos já estabelecidos em Jomtien, traçando novas metas que devem ser exequíveis até 2015. A concepção posta acerca da educação se traduz pelo entendimento de que ela é um direito fundamental e "constitui a chave para um desenvolvimento sustentável", compreendido como a forma que assegure a paz e a estabilidade dentro de cada país e entre eles (UNESCO, 2001, p. 8). Reafirmar esta concepção foi necessário, visto que os resultados dos compromissos de Jomtien foram considerados insuficientes para a maioria dos países em relação à redução nas taxas de analfabetismo adulto e a diminuição das desigualdades na educação das meninas, minorias étnicas e portadores de necessidades especiais.

Segundo o que consta no documento "Educação para todos: o compromisso de Dakar", os países membros deveriam garantir planos setoriais de educação até 2002, a fim de alcançar os objetivos da conferência ao assumirem compromissos que dizem respeito, dentre vários aspectos, à promoção da equidade, à garantia de ambientes seguros e inclusivos de modo a conduzir a excelência na aprendizagem e 
promover políticas de Educação para Todos, "dentro do marco setorial integrado e sustentável, claramente articulado com a eliminação da pobreza e com estratégias de desenvolvimento" (UNESCO, 2001, p. 9).

Para se alcançar a educação para todos, o documento de Dakar estabeleceu 6 metas e 12 estratégias, cujo foco volta-se ao discurso da qualidade da educação, a preocupação com a diversidade, gênero e com as desigualdades. "A promoção de políticas da Educação para Todos dentro de um quadro setorial sustentável e bem integrado, vinculado de maneira clara à eliminação da pobreza e às estratégias de desenvolvimento" (UNESCO, 2001, p. 22), constitui uma forma para concretizar as metas, atribuindo à educação o papel de outorgar ao indivíduo, à eliminação da pobreza no nível de família e da comunidade e ao desenvolvimento social e econômico (UNESCO, 2001).

De modo geral, a Conferência de Dakar vem reforçar o entendimento acerca da educação e seu lugar junto ao desenvolvimento econômico. De Jomtien a Dakar, as reformas propostas para a educação dos países signatários, embora o discurso conservasse alguns termos chaves, a linguagem usada nos documentos oficiais passou, no final dos anos de 1990, do "[...] viés economicista explícito a uma face humanitária por meio da qual a política educacional ocuparia o lugar de solução dos problemas humanos mais candentes em especial o problema da sobrevivência na sociedade atual" (EVANGELISTA; SHIROMA, 2006, p. 44). Segundo as autoras, a concepção presente nos documentos repassa a ideia de sobrevivência na sociedade, cujos laços de solidariedade se constroem entre os indivíduos. Por outro lado, omite as responsabilidades do capital, que a todo custo é defendido, e coloca as soluções para o desenvolvimento sustentável na conta da educação.

Por fim, a Declaração de Incheon, que expressa o resultado do Fórum Mundial de Educação que ocorreu em maio de 2015, na cidade de Incheon - Coréia do Sul faz um balanço da educação, seus avanços e mazelas desde Jomtien e referenda o documento "Educação 2030: rumo a uma educação de qualidade inclusiva e equitativa e à educação ao longo da vida para todos", reafirmando o movimento global da Educação para Todos. O documento expressa o reconhecimento dos esforços feitos para promover o progresso na educação, mas afirma que ainda estamos longe de alcançar a educação para todos. Frente a essa constatação a Declaração propõe, 
rumo a 2030, uma nova visão para a educação com vínculo direto à relação educação e desenvolvimento sustentável:

\begin{abstract}
Nossa visão é transformar vidas por meio da educação ao reconhecer seu importante papel como principal impulsionador para o desenvolvimento e para o alcance de outros $\mathrm{ODS}^{3}$ propostos. Comprometemo-nos, em caráter de urgência, com uma agenda de educação única e renovada, que seja holística, ousada e ambiciosa, que não deixe ninguém para trás. Essa nova visão é inteiramente captada pelo ODS 4 "Assegurar a educação inclusiva e equitativa de qualidade, e promover oportunidades de aprendizagem ao longo da vida para todos" e suas metas correspondentes (UNESCO, 2015, p. 01, gripo do autor).
\end{abstract}

Essa "nova visão" reafirma que a educação é um "bem público, um direito humano fundamental e a base que garante a efetivação de outros direitos", é essencial para "a paz, a tolerância, a realização humana e o desenvolvimento sustentável”, bem como elemento-chave para atingir o "pleno emprego e a erradicação da pobreza". Por isso, o esforço deve estar concentrado na busca da equidade e da inclusão, da qualidade nos resultados da aprendizagem, numa abordagem de educação ao longo da vida (UNESCO, 2015, p. 01).

Para tal fim, afirma a garantia do fornecimento de educação primária e secundária gratuita, equitativa, de qualidade e com financiamento público por 12 anos, sendo no mínimo nove anos de educação obrigatória, além de indicar a educação préprimária de pelo menos um ano e o compromisso de oferecer educação, cuidado e desenvolvimento de qualidade na primeira infância. Além disso, faz referência ao grande número de crianças e adolescentes fora da escola e à necessidade de medidas imediatas para garantir que todas as crianças estejam na escola e aprendendo (UNESCO, 2015).

Os termos inclusão e equidade são destacados no item 7 como o "alicerce de uma agenda de educação transformadora", para o compromisso de "enfrentar todas as formas de exclusão e marginalização", pois, ambiciosamente, o documento afirma que "nenhuma meta de educação deverá ser considerada cumprida a menos que tenha sido atingida por todos". Por isso, a necessidade de concentrar os esforços nas políticas de educação que contemplem os mais desfavorecidos, especialmente as pessoas com deficiências, "a fim de assegurar que ninguém seja deixado para trás".

${ }^{3}$ ODS - Objetivos de Desenvolvimento Sustentável. 
Também referenda a importância da igualdade de gênero para alcançar o direito à educação para todos (UNESCO, 2015, p. 2).

A educação de qualidade e a melhoria dos resultados de aprendizagem são colocadas como um compromisso que exige o "reforço" de insumos e processos, além da avaliação para medir os resultados de aprendizagem. Este "reforço" passa pela formação dos educadores e pela disposição de recursos para que suas ações sejam eficientes e eficazes.

A Declaração reforça que a educação de qualidade assegura a aquisição de habilidades básicas em alfabetização e matemática, bem como habilidades analíticas, capacidade de resolver problemas e habilidades interpessoais e sociais. Vincula a educação de qualidade ao desenvolvimento de

\footnotetext{
habilidades, valores e atitudes que permitem aos cidadãos levar vidas saudáveis e plenas, tomar decisões conscientes e responder a desafios locais e globais por meio da educação para o desenvolvimento sustentável (EDS) e da educação para a cidadania global (ECG) (UNESCO, 2015, p. 2).
}

Para isso, é afirmado o apoio à implementação do Programa de Ação Global sobre EDS ${ }^{4}$, lançado na Conferência Mundial da UNESCO em Aichi-Nagoya, em 2014, que objetivou dar seguimento oficial à Década das Nações Unidas sobre EDS, decorrida entre 2005 e 2014. Nesse sentido, esta declaração enfatiza a ação urgente para fortalecer ainda mais e expandir a EDS, a fim de capacitar as presentes gerações e responder às suas necessidades, sem prejuízo destas às gerações futuras, levando em conta as dimensões econômicas, sociais e ambientais do desenvolvimento sustentável (UNESCO, 2014).

A Declaração Aichi-Nagoya reafirmou o papel da EDS de capacitar os alunos para que transformem a eles próprios e a sociedade em que vivem através dos conhecimentos, competências, atitudes e valores, para enfrentar os desafios globais e os desafios de contexto local do presente e do futuro. Também, destacam que a EDS é uma oportunidade e uma responsabilidade, tanto dos países desenvolvidos como em desenvolvimento de ampliar esforços para "a erradicação da pobreza, redução de desigualdades, proteção do ambiente e crescimento econômico"

\footnotetext{
${ }^{4}$ A Declaração de Aichi-Nagoya, que aconteceu no Japão de 10 a 12/11/2014, faz um apelo a todas as nações para implementarem o Programa de Ação Mundial em EDS (Global Action Programme GAP), para avançar com a agenda de EDS.
} 
(UNESCO, 2014, p. 3), a fim de promover a igualdade, a sustentabilidade nas economias e nas sociedades beneficiando todos os países, mas especialmente os mais vulneráveis e menos desenvolvidos (UNESCO, 2014).

Sobre a implementação da agenda proposta, a Declaração de Incheon reafirma a responsabilidade dos governos e faz um apelo para que haja sólida colaboração, cooperação, coordenação e monitoramento, tanto global quanto regional, para a implementação da agenda de educação [...]" (UNESCO, 2015, p. 3). Reconhece a necessidade de políticas e planejamento sólidos com um aumento significativo e bem orientado do financiamento, para que as aspirações dos Objetivos de Desenvolvimento Sustentável (ODS) possam ser concretizadas, em particular nos países que estão mais distantes de alcançar a educação de qualidade para todos. Para isso a determinação de aumentar a despesa pública em educação, de acordo com o contexto de cada país, e a estimular a adesão aos indicadores internacionais e regionais, para que a o investimento em educação seja de pelo menos $4 \%$ a $6 \%$ do Produto Interno Bruto (PIB) e/ou de pelo menos $15 \%$ a $20 \%$ do total das despesas públicas em educação (UNESCO, 2015).

Em síntese, a Conferência de Incheon explicita o papel da educação para transformação de vidas por meio de uma nova visão, com metas até 2030. A inclusão e a equidade são colocadas como desafio para a qualidade da educação, necessária ao desenvolvimento sustentável e a educação para a cidadania, como forma de diminuir a pobreza.

Portanto, a pauta de reconhecer a educação como central para a integração do indivíduo à ordem global e, assim, a consequente superação da pobreza reafirma velhos compromissos veementemente defendidos desde Jomtien. Contudo, não discute e nem aponta objetivos e metas para "o fim das mazelas produzidas pelo capitalismo, que os ditos organismos multilaterais que atuam em sua defesa tentam, a todo custo, acomodar em suas apertadas estatísticas" (JIMENEZ; MENDES SEGUNDO, 2007, p. 132). Conforme as autoras, a responsabilidade e as estruturas sociais do capital não são mencionadas e o foco da superação da pobreza é colocado como função da educação. Assim, não se trata de propostas para transformar a realidade, mas para conservá-la, o que impõe o empenho de mistificá-la. 


\section{EDUCAÇÃO PARA O DESENVOLVIMENTO SUSTENTÁVEL E ALÍVIO DA POBREZA}

Como vimos, a educação para o desenvolvimento sustentável é um discurso articulado por agências reguladoras internacionais, especialmente a UNESCO. Mas quais os motivos de tamanho interesse na implementação e consolidação de políticas sustentáveis para a educação?

Para responder essa questão, não basta apenas utilizarmos os argumentos das próprias agências, ou seja, a necessidade de diminuir a pobreza e aumentar os níveis de desenvolvimento, tendo a educação como principal elemento. É necessário, portanto, incorrer no percurso histórico e tentar desvendar os motivos que fazem desses órgãos fontes de poder na diretividade das ações. Isso implica em trazer para o debate a figura do Banco Mundial (BM), que se tornou um dos principais financiadores das políticas sociais nos países pobres ou em desenvolvimento.

A partir dos anos de 1960, o BM passou a ser, além de financiador, propositor de políticas educacionais aos países que a ele recorreram. O Banco se alia a decisões e ações de outras instituições como o FMI, o BID, a UNESCO e a UNICEF, dentre outros, atuando como agente político do processo global de desenvolvimento, "entendido como progresso, cujo princípio está relacionado, do ponto de vista positivista, à ideia de crescimento demográfico dos países, pela expansão dos mercados, através do emprego e acúmulo de capital" (CANAN, 2016, p. 52).

No entanto, a ideia de crescimento não eliminou a pobreza dos países, e desse modo, o discurso do progresso é substituído pelo da sustentabilidade, o qual pressupunha "maior economia na utilização de recursos naturais e a necessidade de limitar o crescimento das diferentes nações" (CANAN, 2016, p. 53). Segundo Evangelista e Shiroma (2006, p. 46), "no âmbito dos sentidos que se atribuíram à pobreza, uma primeira perspectiva foi a redistributiva e desenvolvimentista, que marcou os anos de 1960 [...]".

A partir desse período, o BM elaborou uma série de documentos que fizeram emergir novos discursos, como a equidade, a pobreza (entre outros) e também desenvolvimento sustentável. A pobreza ocupa lugar central das preocupações do Banco, cuja solução apontada era a de que o problema dependia mais do aumento da produtividade dos pobres do que o crescimento do país. 
$\mathrm{Na}$ década de 1980, devido à recessão que assolava os países latinoamericanos, o BM continuou atuando como financiador e propositor das políticas sociais, produzindo (desde a década anterior) "um discurso humanitário, respaldado por princípios de sustentabilidade e igualdade social" (CANAN, 2016, p. 56).

Nos anos de 1990, a pobreza adquiriu nova centralidade por parte de Banco Mundial e o discurso alertava para a necessidade de promover o uso produtivo do recurso mais abundante dos pobres: o trabalho. Para atingir esse fim, era necessário prover os pobres de serviços sociais básicos, dentre eles a educação (EVANGELISTA; SHIROMA, 2006).

A partir da década de 1990, o BM passou a se destacar pela sua atuação e organização da Conferência de Jomtien na Tailândia cujos pressupostos se alastraram e consolidaram-se nos encontros posteriores. O papel da educação básica é considerado essencial para o desenvolvimento sustentável e de longo prazo para o alívio da pobreza.

Nesse período, consolidou-se a orientação do neoliberalismo nos programas de reformas dirigidas, cujo papel do Estado passou a ser regulador e, as políticas sociais foram assumidas pelo setor privado, tomando um lugar de destaque na oferta dos serviços sociais (CORSETTI, 2015). Para a autora,

\footnotetext{
A influência dos organismos internacionais, como o Fundo Monetário Internacional (FMI), o Banco Mundial (BM), a Organização das Nações Unidas para a Educação, Ciência e Cultura (UNESCO), a Comissão Econômica para a América Latina e Caribe (CEPAL), entre outros, na estruturação das políticas públicas, é evidente, sobretudo na definição das possíveis saídas para a crise no setor (CORSETTI, 2015, p. 63).
}

Os discursos contidos nos documentos dos organismos internacionais colocavam como vilão da educação, a falta de produtividade, de eficiência e eficácia, ou seja, a educação deveria se alinhar a uma proposta mais eficiente. A partir de então, a pobreza recebeu especial atenção por parte do Banco Mundial.

Em que pese a pobreza permanecer como problema central, seu conceito não é apenas relativo aos indicadores econômicos. Sob seu aspecto cultural, ocidentalizou-se o termo e o diferiu do entendimento dos anos de 1990 que "incidia sobre a ideia (sic) de que para a redução da pobreza seria necessário o uso intensivo da mão-de-obra (sic) aliada a uma ampliação dos serviços sociais" (EVANGELISTA; SHIROMA, 2006, p. 48). 
Já nos anos 2000, o BM mundial apresenta outro conceito de pobreza, ao qual é incorporada a ideia de oportunidade, de autonomia e segurança. Assim, "pobre é aquele que não tem, ou tem poucas "oportunidades" econômicas; que não tem, ou tem pouca "autonomia" no que tange às barreiras sociais derivadas de sua condição de sexo, etnia, raça e status social" (BANCO MUNDIAL, 2000/2001, p. 33 apud EVANGELISTA; SHIROMA, 2006, p. 48). A alteração no conceito de pobreza, segundo as autoras, antes lastreado em aspectos econômicos, agora é visto como um ponto de vista econômico, social e cultual, na perspectiva da carência.

Não é a toa que a educação para o desenvolvimento sustentável proposto nas Conferências analisadas neste estudo, em especial a de Incheon (2015), associa as condições educacionais à sustentabilidade ao pleno emprego e à redução da pobreza. Se por décadas a receita que combinaria educação e crescimento econômico não foi eficaz para sanar problemas sociais, necessário foi alterar o conceito de pobreza, para atribuir a cada indivíduo a capacidade de resolver seus próprios problemas, numa perspectiva mais ampla que não apenas a econômica. Dar o mínimo aos pobres, por meio de reformas educacionais paliativas é, a nosso ver, uma das alternativas para resolver os conflitos sociais e garantir a segurança e a paz mundial.

Se nos anos de 1990 o BM entendia que o uso intensivo da mão de obra gerava desenvolvimento, essa visão modificou-se, ou seja, as análises do Banco observaram o oposto e que os serviços sociais precisavam ser repensados para além do Estado, envolvendo outros atores sociais. Seria necessário oferecer segurança aos pobres, Ihes dar oportunidade e autonomia e, conforme o próprio BM define é fundamental habilitar os pobres. A partir disso, o "discurso - que relaciona educação e combate à pobreza - quer se concretizar pela via da empregabilidade, da educação da menina e da política de inclusão, mobilizando a denominada cidadania ativa" (EVANGELISTA; SHIROMA, 2006, p. 51).

Para as autoras, o trabalho dos pobres, homens e mulheres ganharia importância não pelo que se produz, mas pela ideia de que mesmo o trabalho não pago (voluntário) gera a inclusão, que é considerado como trabalho para a cidadania plena e necessário para resolver problemas. De acordo Jimenez e Mendes Segundo (2007), as ações de apoio do BM em favor da educação como instrumento de alívio da pobreza, estão ligadas a preocupação primordial com a manutenção da estabilidade política e das medidas de ajuste para que a reprodução do lucro avance 
de forma crescente e invasiva sobre o trabalho e a experiência social em geral, aqui incluída a própria atividade educacional, que deve estar a serviço do capital. E completam:

\begin{abstract}
Nesse sentido, para deixar incólumes as "responsabilidades" e as estruturas do capital, evitando, outrossim, despertar ânimos voltados à sua superação, há que se desviar o foco das causalidades, jogando, então, na conta da educação, as soluções para o agravamento da fome no mundo (e, a rigor, também para a guerra do Iraque, a questão palestina, a destruição ecológica do planeta, a corrupção política, a violência urbana...) (JIMENEZ; MENDES SEGUNDO, 2007, p. 133).
\end{abstract}

Nessa breve análise, procuramos demonstrar que a ligação entre o discurso da educação para o desenvolvimento sustentável tem um viés que, a priori, não é dado, tampouco visto, pois como nos alerta Evangelista; Shiroma (2006) não é "no campo da educação que se encontrarão respostas para a pergunta sobre as origens da pobreza ou sua supressão". A pobreza é acompanhada pelas reformas das economias e na procura pelo lucro, o capital, por meio de suas agências, acaba regulando e produzindo acordos que funcionam como instrumentos de intervenção, a fim de garantir, por todos os meios, inclusive pela educação, a reprodução do próprio capital.

\title{
5 CONSIDERAÇÕES FINAIS
}

O desafio proposto nessa reflexão apontava para a discussão sobre a concepção de educação para o desenvolvimento sustentável em documentos oficiais transnacionais. Também, propúnhamos entender o início desses novos discursos que figuram na educação e que já está incorporado em muitas políticas educacionais.

A Educação para o desenvolvimento sustentável tem um marco significativo em 2005, quando a UNESCO sistematiza orientações específicas sobre o tema. No entanto, desde Jomtien (1990), se falava em desenvolvimento humano sustentável, atribuindo à educação tarefa significativa para esse fim. A importância dada para a educação básica aliava conhecimento com desenvolvimento, numa proposta que valorizava a equidade. O que ocorre é que a "Educação para o Desenvolvimento Sustentável (2005)" aparece num momento em que é necessário mudar o discurso, ou seja, o desenvolvimento econômico deve ser substituído pela ideia de 
sustentabilidade. Para tanto, se fortalece o discurso do alívio da pobreza, pois para educação sustentável, é necessário conceder ao indivíduo uma educação básica e conhecimentos sumários, baseados nas oportunidades de inclusão que potencializa o pobre a resolver seus próprios problemas. O que está em jogo não é apenas uma educação que abra possibilidades para a empregabilidade (aquela relativa ao desenvolvimento), mas que oferte condições para se criar oportunidade e autonomia, num processo social inclusivo.

As demais conferências educacionais que seguiram, repetiram o debate já levantado, porém aliado às novas perspectivas e em diferentes tempos históricos. Como nos lembra Evangelista e Shiroma (2006, p. 44), "no início dos anos de 1990, girava em torno de conceito como produtividade, eficiência e eficácia. No final da década, o viés economicista explícito deu lugar a uma face humanitária". Desse modo, segundo as autoras, o campo da política educacional seria o lócus para a solução dos problemas mais graves da sociedade, em especial da sobrevivência na sociedade atual.

A propagada educação para todos, defendida nos documentos, não se concretiza e tem um caráter extremamente limitado e desigual, imposto pelo capital, de acordo com seus interesses quanto à universalização da educação. Não há interesse que nos países da periferia do capitalismo, como o Brasil, sejam efetivados projetos de educação minimamente substantivos, que possam, de fato, contribuir para potencializar processos emancipatórios.

Entendemos que educação para o desenvolvimento sustentável, a guisa dessas reflexões preliminares, se transforma em mais um discurso reformista, cuja superação de modelos externos e voltados ao capital está longe de se efetivar. $O$ embate, nesse sentido, está posto: se por um lado a educação na sociedade capitalista é instrumento de reprodução do capital, também cumpre um papel inquestionável para a formação do ser social que pode alavancar a transformação da sociedade em prol de relações mais justas e igualitárias. Ultrapassar esse discurso se constitui num longo caminho, visto já ter sido incorporado em documentos oficiais das políticas brasileiras, elemento para um próximo debate.

\section{SOLANGE ZOTTI}


Graduada em Pedagogia e em Artes Práticas pela Universidade do Oeste de Santa Catarina. Pós-graduada em Metodologia do Ensino Superior pela Faculdade de Filosofia, Ciências e Letras de Ouro Fino (MG). Mestre em Educação na área de Educação e Ensino pela Universidade Estadual de Campinas (UNICAMP) e doutora em Educação na área de História, Filosofia e Educação pela mesma instituição. Professora do Instituto Federal Catarinense (IFC), Campus Concórdia.

\section{LIANE VIZZOTTO}

Graduada em Pedagogia, habilitação em séries iniciais e educação infantil pela Universidade do Contestado, com especialização na mesma área. Mestre em Educação pela Universidade Federal do Paraná (UFPR) e doutoranda do Programa de Pós-Graduação em Educação da Universidade do Vale do Rio dos Sinos (UNISINOS). Atualmente é Professora do Instituto Federal Catarinense (IFC), Campus Concórdia.

\section{BERENICE CORSETTI}

Graduada em História pela Universidade de Caxias do Sul. Mestre em História pela Universidade Federal Fluminense (UFF). Doutora em Educação pela Universidade Estadual de Campinas (UNICAMP) e pós-doutora em Educação pela mesma instituição. Bolsista produtividade em Pesquisa do CNPQ e professora titular do Programa de Pós-Graduação em Educação da Universidade do Vale do Rio dos Sinos (UNISINOS).

\section{REFERÊNCIAS}

CANAN, S. R. Influência dos Organismos Internacionais nas Políticas Educacionais. Só há intervenção quando há consentimento? Mercado das Letras: Campinas, 2016.

CORSETTI, B. Políticas Educacionais no cenário contemporâneo. In: CORSETTI, B. (org). Avaliação da Educação e Gestão Democrática e indicadores de qualidade: um estudo de caso no Município de Novo Hamburgo/RS. Casa Leiria: São Leopoldo, 2015. p. 61-72.

DELORS, J. Educação um Tesouro a Descobrir: Relatório para a UNESCO da Comissão Internacional sobre Educação para o século XXI. Cortez: UNESCO; MEC, 1994.

EVANGELISTA, O; SHIROMA, E. O. Educação para o alívio da pobreza: novo tópico na agenda global. Revista de Educação PUC - Campinas, n. 20, p. 43-54, jun. 2006.

GADOTTI, M. Significado e desafio da educação básica. International Workshop World University Service (WUS) "Education for All: A Challenge for Democracy and Human Rights". NEW DELHI - INDIA - 6-8 September 1991. Disponível em: < www.acervo.paulofreire.org:8080/jspui/handle/7891/3391>. Acesso em: 28 jul. 2016. 
GUERRA, A. F. S. et al. A temática ambiental e a Sustentabilidade nos cursos de Graduação da UNIVALI: caminhos para a ambientalização curricular na Universidade. In: CARNIATTO, I. et al (Org.) Educação Ambiental. Redes e Sustentabilidade. Curitiba: Universidade Tuiuti, 2015.

JIMENEZ, S. V.; MENDES SEGUNDO, M. d. D. Erradicar a pobreza e reproduzir o capital: notas críticas sobre as diretrizes para a educação do novo milênio. Cadernos de Educação, FaE/PPGE/UFPel, Pelotas ,28, p. 119 - 137, jan./jun. 2007.

LAYRARGUES, P. P. Do ecodesenvolvimento ao desenvolvimento sustentável: evolução de um conceito? In: Proposta, 25 (71), p. 5-10, 1997. Disponível em: $<$ http://www.educacaoambiental.pro.br/victor/biblioteca/Layrarguesecodesenvolvime nto.pdf>. Acesso em: 02 ago. 2016.

LIMA. G. da C. O Discurso da Sustentabilidade e suas implicações para a educação. Ambiente \& Sociedade, v. VI, n. 2, p. 99- 119, jul./dez.2003.

ONUBR. Nações Unidas no Brasil. A ONU e o meio ambiente. Disponível em: $<$ https://nacoesunidas.org/acao/meio-ambiente/>. Acesso em: 22 jul. 2016.

UNESCO. Década das Nações Unidas da Educação para o Desenvolvimento Sustentável: 2005 - 2014: documento final do esquema internacional de implementação. 2005. Disponível em: $<$ http://unesdoc.unesco.org/images/0013/001399/139937por.pdf >. Acesso em: 15 jun. 2016.

UNESCO. Declaração Mundial sobre Educação para Todos: Plano de Ação para Satisfazer as Necessidades Básicas de Aprendizagem. 1990. Disponível em: <http://unesdoc.unesco.org/images/0008/000862/086291 por.pdf >. Acesso em: 10 jun. 2016.

UNESCO. Declaração de Aichi-Nagoya: declaração da educação para o desenvolvimento sustentável. 2014. Documento em construção. Tradução livre da Associação CIDAADS, nov. 2014. Disponível em: <http://unesdoc.unesco.org/images/0023/002305/230514e.pdf>. Acesso em: 12 ago. 2016.

UNESCO. Educação 2030: rumo a uma educação de qualidade inclusiva e equitativa e à educação ao longo da vida para todos. 2015. Disponível em: $<$ http://www.unesco.org/new/pt/brasilia/about-this-office/singleview/news/education 2030 incheon declaration and and framework for ac/\#.V7s 3ialYGPI>. Acesso em: 15 jun. 2016.

UNESCO. Educação para Todos: o Compromisso de Dakar. 2001. Disponível em: < http://unesdoc.unesco.org/images/0012/001275/127509porb.pdf>. Acesso em: 15 jun. 2016. 